\title{
Oleanolic Acid and Ursolic Acid Induce UGT1A1 Expression in HepG2 Cells by Activating PXR Rather Than CAR
}

OPEN ACCESS

Edited by:

Jinyong Peng,

Dalian Medical University,

China

Reviewed by:

Tao Zeng,

Shandong University,

China

Guoxun Chen,

The University of Tennessee,

Knoxville, United States

Feng Li,

Baylor College of Medicine,

United States

*Correspondence:

Chunhua Xia

xch720917@163.com

tThese authors have contributed equally to this work

Specialty section:

This article was submitted to Gastrointestinal and Hepatic

Pharmacology,

a section of the journal

Frontiers in Pharmacology

Received: 02 July 2019

Accepted: 29 August 2019 Published: 27 September 2019

Citation:

Yao N, Zeng C, Zhan T, He F, Liu M, Liu F, Zhang $H$, Xiong $Y$ and Xia $C$ (2019) Oleanolic Acid and Ursolic Acid Induce UGT1A1 Expression in HepG2 Cells by Activating PXR Rather Than CAR.

Front. Pharmacol. 10:1111. doi: 10.3389/fphar.2019.01111
Na Yao ${ }^{1+}$, Caiwen Zeng ${ }^{2 \dagger}$, Tao Zhan ${ }^{1+}$, Fang He ${ }^{3}$, Mingyi Liu ${ }^{1}$, Fanglan Liu ${ }^{1}$, Hong Zhang ${ }^{1}$, Yuqing Xiong ${ }^{1}$ and Chunhua Xia ${ }^{1 *}$

\begin{abstract}
${ }^{1}$ Clinical Pharmacology Institute, Nanchang University, Nanchang, China, ${ }^{2}$ Laboratory of Translational Medicine and Oncology, Jiangxi Province Cancer Hospital, Nanchang, China, ${ }^{3}$ Pharmacy Department, Jiangxi Province Cancer Hospital, Nanchang, China
\end{abstract}

Background: Oleanolic acid (OA) and its isomer ursolic acid (UA) have recently emerged as research foci based on their biologic activities. We previously demonstrated that UA can inhibit the activities of UGT1A3 and UGT1A4, and OA inhibits UGT1A3 activity in liver microsomes. However, whether OA and UA affect the expression of UGT1As in HepG2 cells and the underlying regulatory mechanism remain unclear.

Purpose: The present study aimed to explore the effect of $O A$ and $U A$ on the expression of UGT1As in HepG2 cells and the regulatory mechanisms on UGT1A1 based on the pregnane X receptor (PXR) and constitutive androstane receptor (CAR) signaling pathways.

Methods: We analyzed the effect of OA and UA on UGT1A expression and on the PXR/ CAR regulatory pathway in HepG2 cells, hPXR-silenced HepG2 cells, and hCAR-silenced HepG2 cells by Q-PCR, Western blotting, and dual-luciferase reporter gene assays.

Results: In HepG2 cells, OA and UA both significantly induced the expression of UGT1A1, UGT1A3, UGT1A4, and UGT1A9 and upregulated the expression of PXR. However, OA and UA did not affect CAR expression. A dual-luciferase reporter assay showed that OA and UA could markedly promote PXR-mediated UGT1A1 luciferase activity, whereas OA and UA did not affect CAR-mediated UGT1A1 luciferase activity. In hPXR-silenced HepG2 cells, OA and UA did not elevate UGT1A1 activity compared to the control group. However, the expression of UGT1A1 in hCAR-silenced HepG2 cells was markedly elevated compared to the control group or with non-silenced HepG2 cells treated with OA $(10,20$, and $40 \mu \mathrm{M})$ or $\cup \mathrm{A}(10,20$, and $40 \mu \mathrm{M})$.

Conclusions: OA and UA significantly induce the expression of UGT1A1, UGT1A3, UGT1A4, and UGT1A9 in HepG2 cells, and their induction on UGT1A1 is mediated by PXR activation, not CAR.

Keywords: OA, UA, UGT1A1, PXR, CAR 


\section{INTRODUCTION}

UDP-glucuronosyltransferases (UGTs) are the major conjugation enzymes of phase II metabolism in vivo, which plays a vital role in maintaining the balance of endogenous metabolites (e.g., bile acids, bilirubin, and steroids) and the removal of exogenous metabolites (e.g., drugs, environmental chemicals, and dietary constituents) (Haberkorn et al., 2002; Manevski et al., 2013; Street et al., 2017). In humans, UGTs are divided into two main subfamilies, namely, UGT1 (e.g., UGT1As) and UGT2, based on amino acid sequence identity (Tukey and Strassburg, 2000). Most of the UGTs are expressed in the liver, including UGT1A1, UGT1A3, UGT1A4, UGT1A6, UGT1A9, UGT2B4, UGT2B7, UGT2B10, UGT2B11, UGT2B15, UGT2B17, and UGT2B28, whereas UGT1A7, UGT1A8, UGT1A10, and UGT2A1 are distributed in extrahepatic tissues (Mackenzie et al., 2005; Nakamura et al., 2008).

UGT1A1, which is known as a bilirubin metabolic enzyme, is one of the most concerned UGT isoforms and is involved in the metabolism of various drugs (e.g., etoposide, trafloxacin, and flavonoids) and important endogenous substances (e.g., bilirubin metabolism and irinotecan detoxification) (Wen et al., 2007; Kapitanović et al., 2009; Yeh et al., 2016). Changes in UGT1A1 activity may lead to alterations in drug metabolism and increased risk for clinical drug-drug interactions. For example, a decrease of UGT1A1 activity reduces glucuronidation of SN-38 (a pharmacologically active metabolite of the anticancer drug, irinotecan), leading to an increased risk for the development of severe irinotecan-associated toxicity (Takano and Sugiyama, 2017). Hence, it is important and significant to investigate the regulation of the UGT1A1 gene for the prevention and treatment of bilirubin metabolic disease and clinical drug-drug interactions.

In general, UGTs are regulated by a group of transcription factors, including the constitutive androstane receptor (CAR), pregnane $\mathrm{X}$ receptor (PXR), aryl hydrocarbon receptor (AhR), and peroxisome proliferator-activated receptor alpha (PPARa) (Bock, 2010). In a more recent report, the UGT1A1 5'-upstream 290-bp region, which contains multiple CAR-, PXR-, and AhRresponse elements, was found to be inducible in response to flavonoids and xenobiotics (Sugatani et al., 2004). Several studies have shown that the expression of bilirubin-detoxifying enzymes and transporters is regulated by the transcription control of the orphan nuclear receptor PXR and CAR, and they confirmed that UGT1A1 is a target gene for PXR and CAR (Maglich et al., 2002; Xie et al., 2003). CAR and PXR are characterized by the presence of a DNA-binding domain (DBD) with two zinc finger motifs and

Abbreviations: OA, oleanolic acid; UA, ursolic acid; PXR, pregnane X receptor; CAR, constitutive androstane receptor; UGTs, UDP-glucuronosyltransferases; UGT1A1, UDP-glucuronosyltransferase 1A1; Q-PCR, quantitative real-time polymerase chain reaction analysis; $\mathrm{SN}-38$, 7-Ethyl-10-hydroxycamptothecin; RXR, retinoid X receptor; RIF, rifampicin; CITCO, Six-(4-chlorophenyl)imidazo $(2,1-b)(1,3)$ thiazole-5-carbaldehydeO-(3,4-dichlorobenzyl)oxime; DMSO, dimethyl sulfoxide; DMEM, Dulbecco's modified Eagle's Medium; FBS, fetal bovine serum; BCA, bicinchoninic acid assay; hCAR shRNA, shRNA against human CAR; hPXR shRNA, shRNA against human PXR; shNC, negative control non-silencing RNA. a conserved ligand-binding domain (LBD), which, in addition to the ligand-binding site, contains dimerization motifs and transactivation domains (Stanley et al., 2006). Both CAR and PXR form heterodimers with retinoid $\mathrm{X}$ receptor (RXR) and bind to the enhancer region of target genes, mediating the transcription of target genes (Kliewer et al., 2015). Xie et al. (2003) found that activated PXR and CAR can induce UGT1A1 and UGT1A6 expression via strong binding with the elements of DR-3 in the upstream of the promoters for PXR and CAR. In addition, some studies have shown that rifampicin and phenobarbital mediate the transcriptional activity of UGT1A1 via the PXR and CAR signal pathway, respectively (Sugatani et al., 2005; Sugatani et al., 2012).

$\mathrm{OA}$ and UA are pentacyclic triterpenoid isomers that are widely distributed in various plants. Studies have demonstrated that OA and UA possess several bioactivities, such as hepatoprotection, anti-tumor, and anti-inflammatory bioactivities (Victor et al., 2015; Kashyap et al., 2016). We previously reported that UA is mainly metabolized by UGTs, and UGT1A3 and UGT1A4 are the main enzymes responsible for the glucuronidation of UA in humans (Gao et al., 2016). Additionally, we showed that UA undergoes competitive inhibition with both UGT1A3 and UGT1A4, and OA exhibits mixed competitive inhibition with UGT1A3. In vivo and in vitro predictions suggest that UA and $\mathrm{OA}$ are more likely to interact in vivo when co-administered with UGT1A3 or UGT1A4 substrates (Xie et al., 2017). However, whether UA and OA influence the expression of UGTs in HepG2 cells and whether the regulation is associated to the PXR and CAR signaling pathway remain unclear.

Therefore, the purpose of this study was to investigate the effect of OA and UA on the expression of UGT1A in HepG2 cells and the underlying regulatory mechanisms based on the PXR and CAR signaling pathway using HepG2 cells, hPXR-silenced, or hCAR-silenced HepG2 cells.

\section{MATERIALS AND METHODS}

\section{Reagents and Chemicals}

OA (purity $\geq 94.9 \%$ ) and UA (purity $\geq 98.0 \%$ ) were purchased from the National Institute for the Control of Pharmaceutical and Biological Products (Beijing, China). Rifampicin (RIF, purity $\geq 97.0 \%$ ) was purchased from Sigma-Aldrich (St. Louis, MO, USA). Six-(4-chlorophenyl)imidazo $(2,1-b)(1,3)$ thiazole5-carbaldehyde O-(3,4-dichlorobenzyl) oxime (CITCO, purity 98.0\%) was purchased from APExBIO Company (Beijing, China). Dulbecco's modified Eagle's Medium (DMEM), fetal bovine serum (FBS), and other cell culture reagents were procured from Hyclone (Logan, UT, USA). Primers for the UGT1A1, UGTA3, UGT1A4, UGT1A9, PXR, CAR, and GAPDH genes for quantitative real-time polymerase chain reaction (Q-PCR) were commercially synthesized by Sangon Biotech Co., Ltd (Shanghai, China). Antibodies used for immunoblot detection, including anti-human UGT1A1, UGT1A3, UGT1A4, and UGT1A9 antibody were all from Abcam (Cambridge, MA, USA). Rabbit polyclonal PXR and CAR antibody were obtained from Proteintech (Chicago, IL, USA). Mouse polyclonal anti$\beta$-actin antibody was obtained from Sigma Co., Ltd (St. Louis, 
MO, USA). Mouse polyclonal anti-Lamin B1 antibody was obtained from Santa Cruz biotechnology Co., Ltd (Santa Cruz, CA, USA). The dual-luciferase reporter assay system was purchased from Promega (Madison, WI, USA). The SuperFectin II DNA transfection reagent was purchased from PUFEI Biology (Shanghai, China). All of the other chemicals and solvents were of the highest grade or analytical grade commercially available.

\section{Plasmids}

The UGT1A1 reporter gene plasmid containing UGT1A1 5 '-upstream 290-bp distal enhancer module $(-3,483 /-3,194)$ with the PXR-, AhR-, and CAR-binding sites was constructed by Maijie Biotechnology Co., Ltd (Nantong, Jiangsu, China) (Sugatani et al., 2004b). The reporter gene was from human genomic DNA and cloned into the pGL3-promoter vector (Promega), namely, pGL3-UGT1A1. The expression plasmid pcDNA3.1 (+)-hCAR containing the full-length human CAR, expression plasmid pcDNA3.1 (+)-hPXR containing the fulllength human PXR, pGL3-Basic, and pcDNA3.1 (+) were provided by Maijie Biotechnology Co., Ltd (Nantong, Jiangsu, China). The pRL-TK renilla luciferase plasmid was obtained from Promega and used to normalize firefly luciferase activities.

\section{Cell Culture and Treatment}

The HepG2 cells were obtained from Boster Biological Technology Co., Ltd (Wuhan, China). In our study, hPXR-silenced HepG2 and hCAR-silenced HepG2 cell models were successfully constructed by respectively transfecting shPXR and shCAR plasmids using the SuperFectin II DNA transfection reagent (PUFEI Biology) following the manufacturer's instructions. The HepG2 cells were cultured in Dulbecco's modified Eagle's medium (DMEM) with 10\% FBS at $37^{\circ} \mathrm{C}$ in a humidified $5 \% \mathrm{CO}_{2}$ atmosphere. Cell passages were performed with $0.25 \%$ trypsin-EDTA (Gibco, Life Technologies) when cells reached $80-90 \%$ confluency. For the treatments, OA, UA, RIF, or CITCO was dissolved in dimethyl sulfoxide (DMSO) for the final stock solution concentrations of 20,20,50, and $50 \mathrm{mM}$, respectively and diluted with DMEM containing 10\% FBS. The final concentration of DMSO never exceeded $0.1 \%(\mathrm{v} / \mathrm{v})$ in the medium.

\section{Quantitative Real-Time Polymerase Chain Reaction Analysis}

Total RNA was extracted from HepG2 cells using TRIzol (Invitrogen, Grand Island, NY, USA) according to the manufacturer's instructions. Total RNA with an $\mathrm{OD}_{260} / \mathrm{OD}_{280}$ between 1.8 and 2.0 was used for qRT-PCR. Approximately $2 \mu \mathrm{g}$ of total RNA from each sample was reversely transcribed into cDNA using a PrimeScript RT reagent kit (TaKaRa Biotech, Kyoto, Japan). Real-time PCR was performed using a PrimeScript ${ }^{\mathrm{Tm}}$ RT-PCR kit (TaKaRa Biotech, Kyoto, Japan) according to the manufacturer's instruction in a Thermal Cycler Dice Real Time System. All of the samples were quantified using a comparative threshold PCR cycle $\left(C_{t}\right)$ method for relative quantification of gene expression, normalized to that of glyceraldehyde-3-phosphate dehydrogenase (GAPDH). The primer sequences are listed in Table 1.

\section{Western Blotting Analysis}

Total protein fractions were extracted using the RIPA lysis buffer (Solarbio Co., Ltd, Beijing), and nuclear protein fractions were extracted from HepG2 cells, hPXR-silenced HepG2 cells and hCARsilenced HepG2 cells using a nuclear extraction kit (Active Motif, Carlsbad, CA, USA) according to the manufacturer's instruction. Protein concentrations were measured with bicinchoninic acid assay (BCA) protein assay (Vazyme Biotech Co., Ltd., Nanjing, China). Protein samples $(50 \mu \mathrm{g})$ were subjected to $10 \%$ sodium dodecyl sulfate-polyacrylamide gel electrophoresis (SDS-PAGE) and electrophoretically transferred onto a polyvinylidene fluoride (PVDF) membrane (EMD Millipore, Bedford, MA, USA). Subsequently, the membranes were blocked with $5 \%$ skim milk for $2 \mathrm{~h}$ and then incubated at $4^{\circ} \mathrm{C}$ overnight with primary antibodies, including UGT1A1 (1:1,000; ab194697, Abcam, Cambridge, MA, USA), UGT1A3 (1:2,000; ab57400, Abcam), UGT1A4 (1:1,000; ab192424, Abcam), UGT1A9 (1:1,000; ab96214, Abcam), PXR (1:2,000; Proteintech, Chicago, IL, USA), CAR (1:2,000; Proteintech, Chicago, IL, USA), $\beta$-actin (1:5,000; Sigma Co., Ltd., USA), and Lamin B1 (1:5,000; Santa Cruz, CA, USA). Then, the membrane was incubated for $1 \mathrm{~h}$ with secondary horseradish peroxidase-conjugated anti-rabbit or anti-rat IgG antibody (1:5,000; Santa Cruz, CA, USA). Subsequently, signals were detected by SuperSignal West Dura (Pierce, Rockford, IL) using a Bio-Rad ChemiDoc XRS imaging system (Bio-Rad Laboratories). Densitometry analysis was performed using Image Lab software (Bio-Rad Laboratories). Mouse polyclonal anti- $\beta$-actin and mouse polyclonal anti-Lamin B1 antibody were used as loading control for total proteins and nuclear proteins, respectively.

\section{Transient Co-Transfection and Luciferase Reporter Assays}

HepG2 cells were cultured in high-glucose (4.5 g/L) DMEM with $10 \%$ FBS. The cells were cultured in a 24 -well plate

TABLE 1 | Primer sequences used for qRT-PCR.

\begin{tabular}{lll}
\hline Gene & Forward primer $\left(\mathbf{5}^{\prime} \rightarrow \mathbf{3}^{\prime}\right)$ & Reverse primer $\left(\mathbf{5}^{\prime} \rightarrow \mathbf{3}^{\prime}\right)$ \\
\hline UGT1A1 & CCTTGCTCAGAATTCCTTC & ATTGATCCCAAAGAGAAAACCAC \\
UGT1A3 & TGTTGACAATATGTCTTGGTCT & CACAGGACTGTCTGAGGGATIIT \\
UGT1A4 & CCTGCTGTGTIIITGGAGGT & ATTGATCCCAAAGAGAAACCAC \\
UGT1A9 & GAACATTATTATGCCACCG & ATTGATCCCAAAGAGAAACCAC \\
PXR & TGTCGGCATCACAGGTAGC & GGCTCTGGCAGTGTCCATC \\
CAR & GCTGGCATGAGGAAAGACAT & CGGATCAGCTCTTCTTGCTC \\
GAPDH & CAGGAGGCATTGCTGATGAT & GAAGGCTGGGGCTCATT
\end{tabular}


to $70-80 \%$ confluency before transfection. At $1 \mathrm{~h}$ before transfection, DMEM with 10\% FBS was replaced with fresh Dulbecco's Modified Eagle Medium (DMEM). The HepG2 cells were transfected with plasmids using SuperFectin transfection reagent according to the manufacturer's instructions. Each well was incubated with $500 \mathrm{ng}$ of mixed plasmid DNA for $5 \mathrm{~h}$. Empty expression vectors were added to equalize the total amount of plasmid DNA transfected in each assay. For the PXR transactivation assay, each well contains $320 \mathrm{ng}$ of pGL3-UGT1A1-luc/pGL3-Basic, $160 \mathrm{ng}$ of pcDNA $3.1(+)-\mathrm{hPXR} / \mathrm{pcDNA} 3.1(+)$ and $20 \mathrm{ng}$ of pRL-TK renilla luciferase plasmid. For CAR transactivation assay, each well contained 384 ng of pGL3-UGT1A1-luc/pGL3-Basic, 96 ng of pcDNA $3.1(+)$-hCAR/pcDNA3.1 (+), and $20 \mathrm{ng}$ of pRL-TK renilla luciferase plasmid. After $5 \mathrm{~h}$ of transfection, the HepG2 cells were treated with $\mathrm{OA}(10,20$, and $40 \mu \mathrm{M})$, UA $(10,20$, and $40 \mu \mathrm{M})$ and respective positive agonist CITCO $(10 \mu \mathrm{M})$ or RIF $(10 \mu \mathrm{M})$ for $24 \mathrm{~h}$ (Tolson and Wang, 2010). DMSO (0.1\%) was used as the negative control. Subsequently, the cells were lyzed in the passive lysis buffer $(1 \times$ PLB) (Promega). The total cell lysates were carefully harvested into the pre-labeled $1.5 \mathrm{ml}$ Eppendorf tubes and then quickly centrifuged at 10,000 rpm for $30 \mathrm{~s}$. The activities of the firefly and Renilla luciferases were assessed using the Dual-Luciferase Reporter Assay System (Promega). The Renilla luciferase activity was used as an internal control. The firefly luciferase activity was normalized against the Renilla luciferase activity, and the ratios of normalized luciferase activity from each tested extract over DMSO treatment were served as relative luciferase activity or fold of induction. Each experiment was repeated three times in triplicate.

\section{RNA Interference}

ShRNA against human CAR (hCAR shRNA) and negative control non-silencing RNA (hCAR shNC) were purchased from the Maijie Biotechnology Co., Ltd. (Nantong, Jiangsu, China). ShRNA against human PXR (hPXR shRNA) and negative control non-silencing RNA (hPXR shNC) were obtained from Novobio Biotechnology Co., Ltd. (Shanghai, China). The target sequence of hCAR shRNA was as follows: GCAUGAGGAAAGACAUGAU. The target sequence of hCAR shNC was as follows: TTCTCC GAACGTGTCACGT. The target sequence of hPXR shRNA was as follows: Forward 5' -CACCGGAGGTGAGACCCAAAGAAA GCGAAC TTTCTTTGGGTCTCACCTCC-3' and Reverse 5'-AAAAGGAGGTGAGACCC AAAGAAAGTTCGCTTTC TTTGGGTCTCACCTCC-3'. The target sequence of hPXR shNC was as follows: Forward 5'-CACCGCTACACAAATCA GCGATTTCGAAAAATCGCTGATTTGTGTAG-3' and Reverse 5'-AAAACTAC ACAAATCAGCGATTTTTCGAAAT CGCTGATTTGTGTAGC-3'. The hCAR shRNA, hCAR shNC, hPXR shRNA, and hPXR shNC were all confirmed by sequencing. The HepG2 cells were seeded into 6-well or 12-well plates for $24 \mathrm{~h}$ and transfected with hCAR shRNA, hCAR shNC, hPXR shRNA, or hPXR shNC using SuperFectin transfection reagent according to the manufacturer's instructions. Knock-down efficiency of shRNAs was determined by Western blotting and real-time
Q-PCR analysis as earlier described. After the success of CAR or PXR gene knock-out, the HepG2 cells were treated with OA (10, 20 , and $40 \mu \mathrm{M})$, UA $(10,20$, and $40 \mu \mathrm{M})$ and respective positive agonist CITCO $(10 \mu \mathrm{M})$ or RIF $(10 \mu \mathrm{M})$. DMSO $(0.1 \%)$ was used as the negative control. Subsequently, Western blotting and realtime Q-PCR analysis were performed.

\section{Statistical Analysis}

All of the experiments were repeated at least three times, and the data are expressed as the mean \pm standard deviation (SD). Statistically significant differences were assessed using one-way analysis of variance (ANOVA) followed by a post hoc Dunnett's test or Student's t-test where appropriate. Values of $\mathrm{P}<0.05$ were considered to be statistically significant: ${ }^{\star} \mathrm{P}<0.05,{ }^{\star *} \mathrm{P}<0.01$, and ${ }^{* * *} \mathrm{P}<0.001$.

\section{RESULTS}

\section{Effect of OA and UA on UGT1As, PXR, and CAR mRNA and Protein Levels in HepG2 Cells}

To explore the effect of OA and UA on UGT1As, PXR, and CAR, we determined the mRNA and protein levels of UGT1As (UGT1A1, UGT1A3, UGT1A4, and UGT1A9), intranuclear PXR and CAR in HepG2 cells treated with OA (10, 20, and $40 \mu \mathrm{M})$, UA $(10,20$, and $40 \mu \mathrm{M})$, CITCO $(10 \mu \mathrm{M})$ and RIF $(10 \mu \mathrm{M})$ for $24 \mathrm{~h}$ using real-time Q-PCR and Western blotting assays. The results showed that $\mathrm{OA}(10,20$, and $40 \mu \mathrm{M})$ significantly upregulated UGT1A1 and UGT1A4 mRNA and protein levels in a concentration-dependent manner compared to the control group in HepG2 cells. Similarly, UGT1A3 and UGT1A9 mRNA and protein expression were significantly induced in HepG2 cells treated with OA. Specifically, $20 \mu \mathrm{M}$ OA exhibited a highest inductive effect on UGT1A3 and UGT1A9. However, UA $(10,20$, and $40 \mu \mathrm{M})$ significantly promoted UGT1A1, UGT1A3, UGT1A4, and UGT1A9 mRNA and protein expression in a concentration-dependent manner (Figures 1 and 2).

Some studies have indicated that PXR and CAR were localized to the cytoplasm and are translocated into the nucleus after ligand treatment (Kliewer et al., 2015). Thus, the nuclear fractions were extracted from HepG2 cells and then used to explore nuclear translocation of PXR and CAR. The results showed that PXR mRNA and intranuclear protein expression were induced in a concentration-dependent manner in HepG2 cells when treated with OA $(10,20$, and $40 \mu \mathrm{M})$ and UA (10, 20 , and $40 \mu \mathrm{M}$ ) (Figure 3). However, no detectable effect on CAR mRNA and protein expression was observed in HepG2 cells treated with OA $(10,20$, and $40 \mu \mathrm{M})$ and UA $(10,20$, and $40 \mu \mathrm{M})$ (Figure 4). The induction trend of UGT1As elicited by OA/UA was similar to that of PXR, which indicated that PXR may regulate the induction of UGT1As in HepG2 cells treated with OA and UA. To further confirm the underlying regulation mechanism of OA and UA on UGT1As, UGT1A1 was selected as the research objective in the subsequent study. 


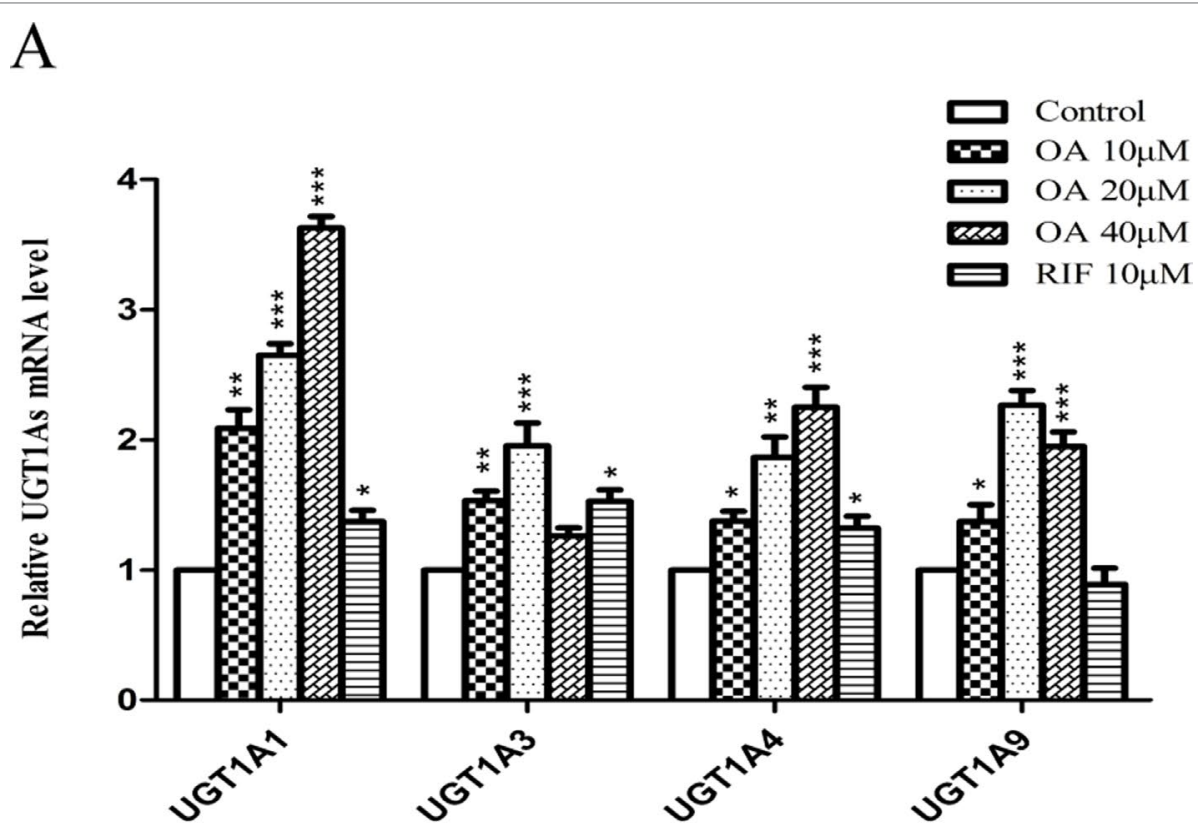

B

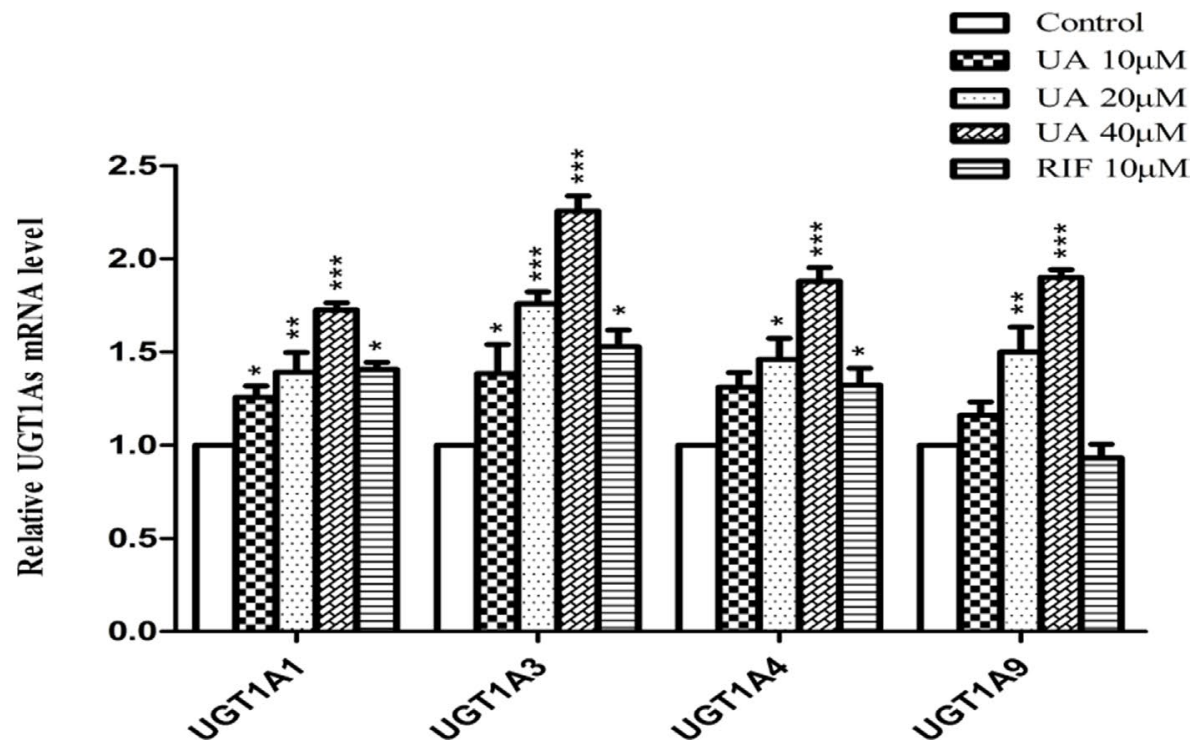

FIGURE 1 | Effect of OA and UA on UGT1A mRNAs in HepG2 cells. The effect of OA (10, 20, and $40 \mu \mathrm{M})$ (A) and UA (10, 20 , and $40 \mu \mathrm{M})$ (B) on UGT1As (UGT1A1, UGT1A3, UGT1A4, and UGT1A9) mRNA expression in HepG2 cells was quantified by real-time Q-PCR analysis, normalized to GAPDH, and compared to the control group. DMSO $(0.1 \%)$ was used as the negative control. RIF $(10 \mu \mathrm{M})$ was used as the positive controls. The data are expressed as the mean \pm SD of triplicate independent experiments $\left({ }^{\star} \mathrm{p}<0.05,{ }^{\star *} \mathrm{p}<0.01,{ }^{\star * *} \mathrm{p}<0.001\right)$.

\section{Effect of OA and UA on the UGT1A1 Reporter Gene in HepG2 Cells Transiently Transfected With hPXR or hCAR}

To explore whether PXR and CAR take part in the regulation of UGT1A1 in the presence of UA and OA, we successfully established the PXR or CAR-mediated UGT1A1 reporter gene in HepG2 cells by transient co-transfection (Figures 5 and 6). The data on how to calculate the fold induction are shown in Tables 2 and 3. Figure 5A shows that RIF (10 $\mu \mathrm{M})$, which was used as the positive control (Tolson and Wang, 2010), significantly increased the PXR-mediated UGT1A1 luciferase activity by 2.83 -fold. OA induced the PXR-mediated UGT1A1 luciferase activity by 1.40 -fold $(10 \mu \mathrm{M}), 1.59$-fold (20 $\mu \mathrm{M})$ and 1.89 -fold $(40 \mu \mathrm{M})$, respectively, while UA induced 
A
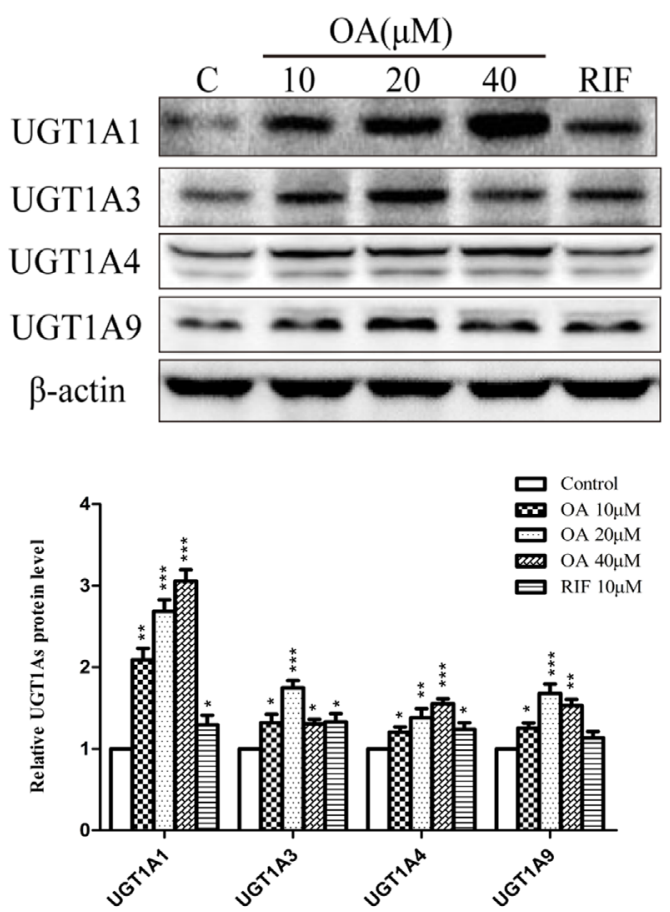

B

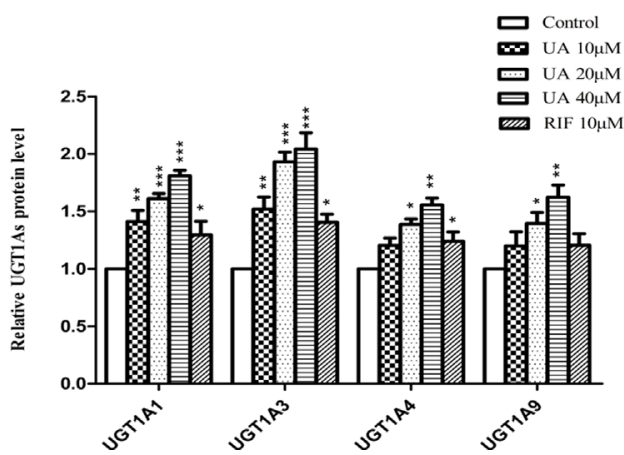

FIGURE 2 | Effect of OA and UA on UGT1A proteins in HepG2 cells. The effect of OA (10, 20, and $40 \mu \mathrm{M})$ (A) and UA (10, 20, and 40 $\mu$ M) (B) on UGT1As (UGT1A1, UGT1A3, UGT1A4, and UGT1A9) protein expression in HepG2 cells was quantified by Western blotting analysis, normalized to $\beta$-actin, and compared to the control group. DMSO (0.1\%) was used as negative control. RIF $(10 \mu \mathrm{M})$ was used as the positive control. The data are expressed as the mean \pm SD of triplicate independent experiments $\left({ }^{*} p<0.05,{ }^{* \star} p<0.01,{ }^{\star * \star} p<0.001\right)$.

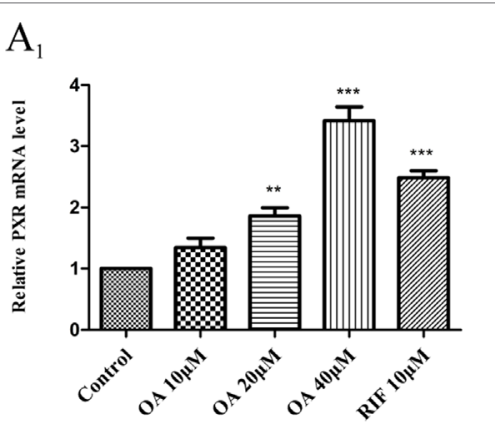

$\mathrm{A}_{2}$

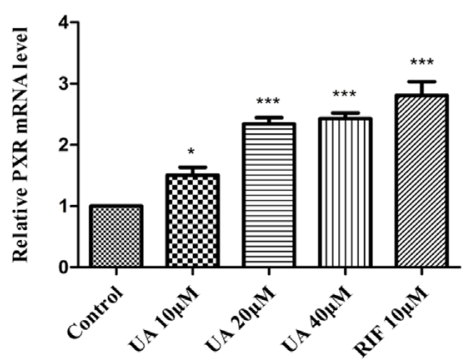

$\mathrm{B}_{1}$

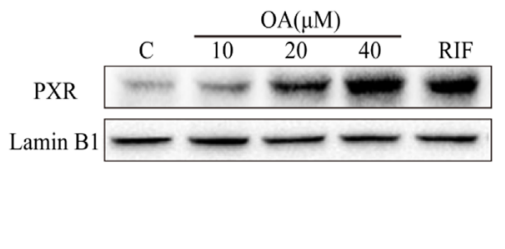

$\mathrm{B}_{2}$

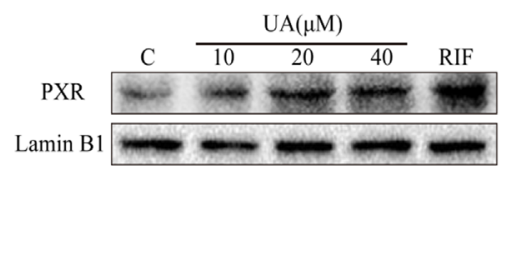

$\mathrm{C}_{1}$

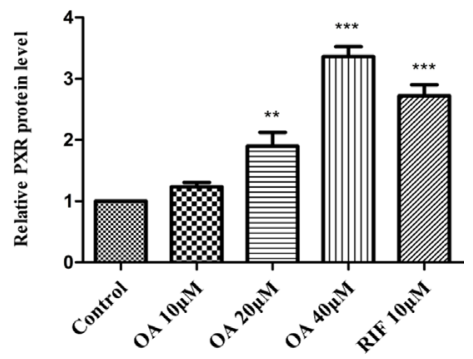

$\mathrm{C}_{2}$

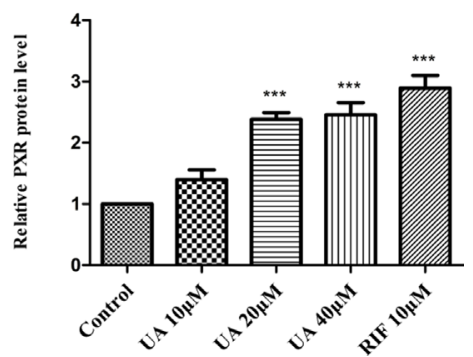

FIGURE 3 | Effect of OA and UA on PXR mRNA and protein in HepG2 cells. The HepG2 cells were treated with OA (10, 20, and 40 $\mu$ M) ( $\mathbf{A}_{\mathbf{1}}-\mathbf{C}_{\mathbf{1}}$ ) and UA (10, 20, and 40 $\mu \mathrm{M})\left(\mathbf{A}_{2}-\mathbf{C}_{2}\right)$ for $24 \mathrm{~h}$. The effect of OA and UA on PXR mRNA and protein expression in HepG2 cells was measured by real-time Q-PCR analysis (A) and Western blotting analysis (B-C). The determination of mRNA and nuclear protein was normalized to GAPDH and Lamin B1, respectively. DMSO (0.1\%) was used as the negative control. $\mathrm{RIF}(10 \mu \mathrm{M})$ was used as the positive control. The data are expressed as the mean $\pm \mathrm{SD}$ of triplicate independent experiments $\left({ }^{\star} \mathrm{p}<0.05\right.$, $\left.{ }^{\star \star} \mathrm{p}<0.01,{ }^{\star \star \star} \mathrm{p}<0.001\right)$. 


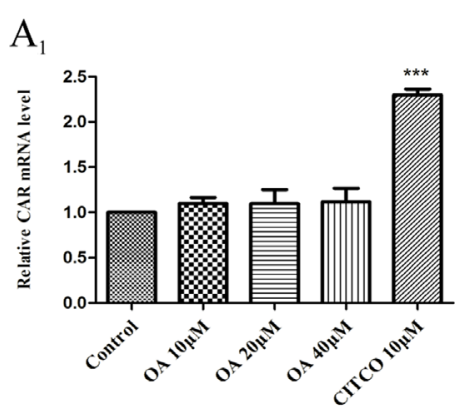

$\mathrm{B}_{1}$

$\mathrm{A}_{2}$

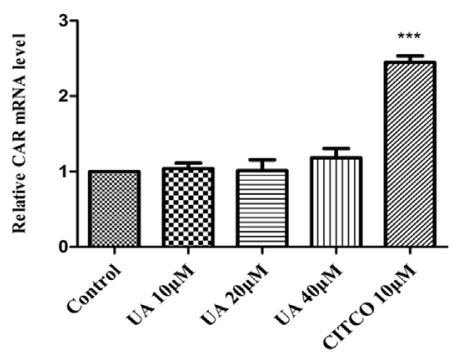

$\mathrm{B}_{2}$

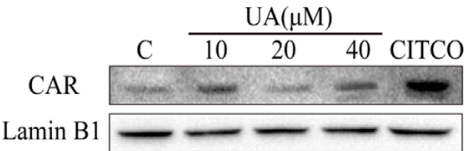

$\mathrm{C}_{1}$

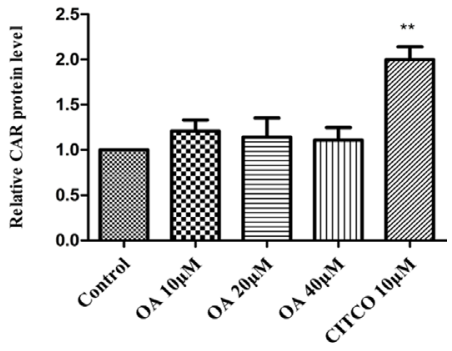

$\mathrm{C}_{2}$

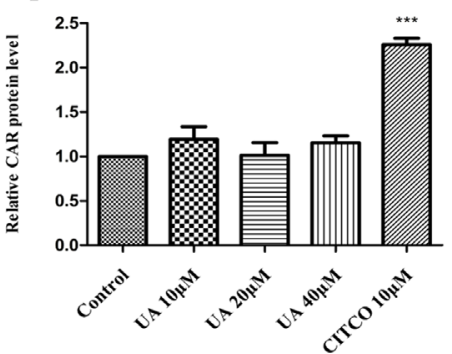

FIGURE 4 | Effect of OA and UA on CAR mRNA and protein in HepG2 cells. The HepG2 cells were treated with OA (10, 20, and $40 \mu \mathrm{M})\left(\mathbf{A}_{1}-\mathbf{C}_{1}\right)$ and UA (10, 20, and $40 \mu \mathrm{M})\left(\mathbf{A}_{2}-\mathbf{C}_{2}\right)$ for $24 \mathrm{~h}$. Effect of OA and UA on CAR mRNA and protein expression in HepG2 cells was measured by real-time Q-PCR analysis (A) and Western blotting analysis (B-C). The determination of mRNA and nuclear protein was normalized to GAPDH and Lamin B1, respectively. DMSO (0.1\%) was used as the negative control. CITCO $(10 \mu \mathrm{M})$ was used as the positive control. The data are expressed as the mean \pm SD of triplicate independent experiments ${ }^{* \star} \mathrm{p}<0.01$, $\left.{ }^{\star \star \star} \mathrm{p}<0.001\right)$.
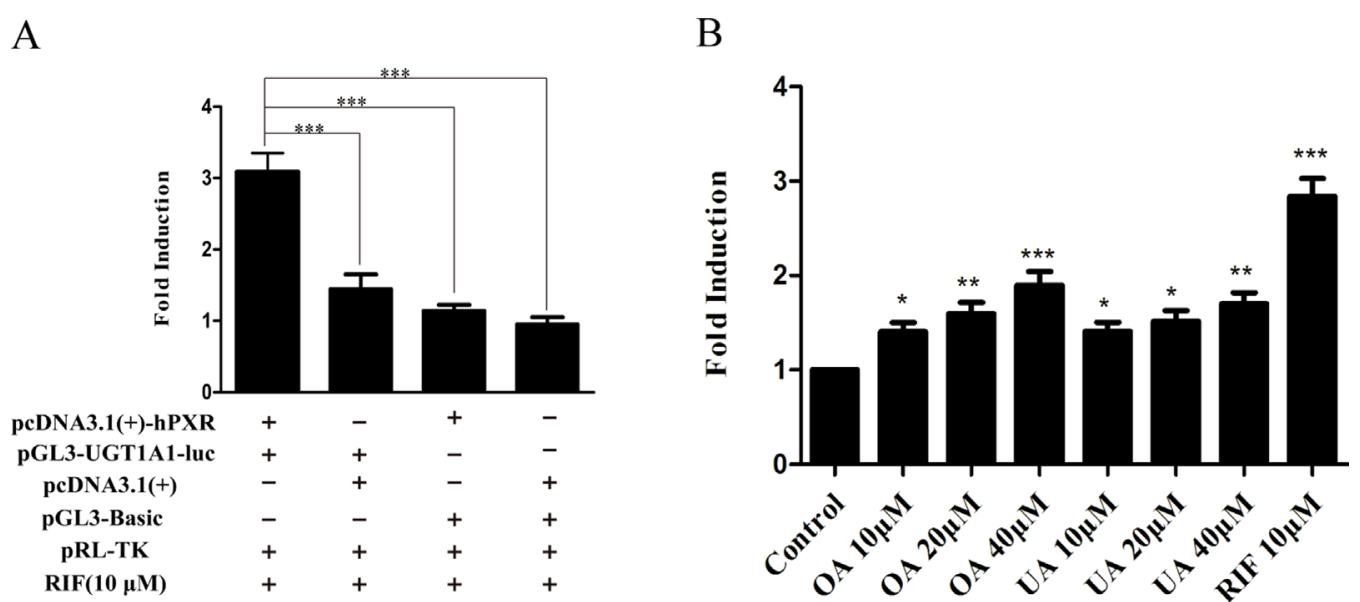

FIGURE 5 | Effect of OA and UA on the UGT1A1 reporter gene in HepG2 cells transiently transfected with hPXR. The HepG2 cells were transfected with pcDNA 3.1 (+)-hPXR, pcDNA 3.1 (+), pGL3-UGT1A1-luc, and/or pGL3-Basic, together with pRL-TK control vector. After transfection for 24 h, the transfected HepG2 cells were cultured with RIF $(10 \mu \mathrm{M})$ or vehicle DMSO $(0.1 \%)$ for an additional $24 \mathrm{~h}$ (A). The HepG2 cells were transiently co-transfected with pcDNA 3.1 (+)-hPXR expression vector, pGL3-UGT1A1-luc reporter vector, and pRL-TK control vector. After transfection for $24 \mathrm{~h}$, the transfected HepG2 cells were cultured with OA (10, 20 , and 40 $\mu \mathrm{M}), \mathrm{UA}(10,20$, and $40 \mu \mathrm{M}), \mathrm{RIF}(10 \mu \mathrm{M})$, or DMSO $(0.1 \%)$ for an additional $24 \mathrm{~h}$ (B). Luciferase activity was measured using the dual-luciferase reporter assay system. The transfection efficiency was normalized against renilla luciferase activity from the co-transfected pRL-TK vector. DMSO (0.1\%) was used as the negative control. RIF $(10 \mu \mathrm{M})$ was used as the positive control. The data are expressed as the mean \pm SD of triplicate independent experiments $\left({ }^{\star} p<0.05,{ }^{\star *} p<0.01,{ }^{\star \star \star} p<0.001\right)$.

the PXR-mediated UGT1A1 luciferase activity by 1.40 -fold $(10 \mu \mathrm{M}), 1.51$-fold $(20 \mu \mathrm{M})$, and 1.70 -fold $(10 \mu \mathrm{M})$, respectively (Figure 5B). CITCO $(10 \mu \mathrm{M})$, which was used as positive control (Tolson and Wang, 2010), significantly increased the CAR-mediated UGT1A1 luciferase activity by 1.90 -fold (Figure 6A). However, OA $(10,20$, and $40 \mu \mathrm{M})$ and UA (10, 20 , and $40 \mu \mathrm{M})$ had almost no significant impact on the CARmediated UGT1A1 luciferase activity (Figure 6B). 
A

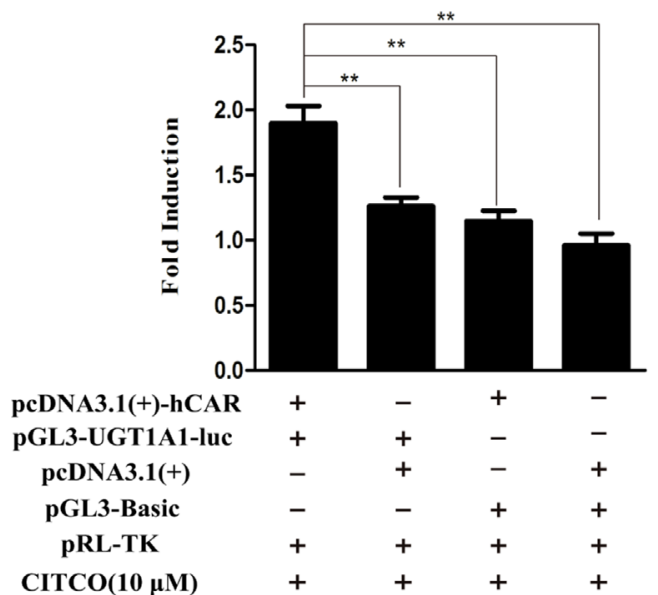

B

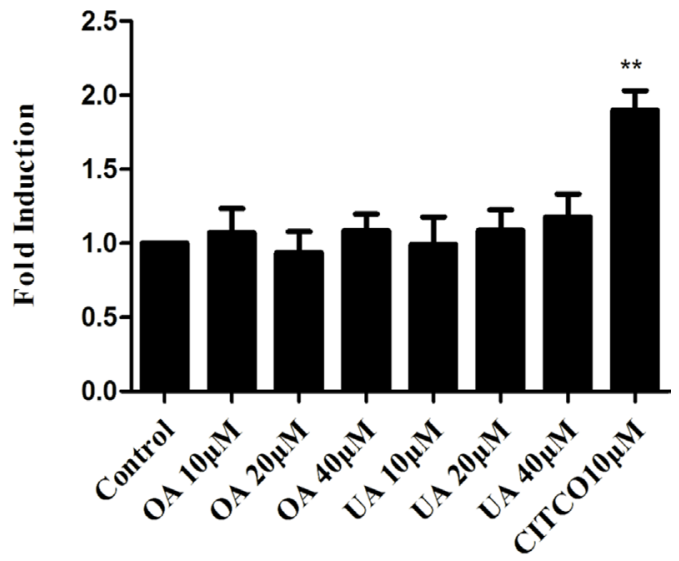

FIGURE 6 | Effect of OA and UA on the UGT1A1 reporter gene in HepG2 cells transiently transfected with hCAR. The HepG2 cells were transfected with pcDNA 3.1 (+)-hCAR, pcDNA 3.1 (+), pGL3-UGT1A1-luc, and/or pGL3-Basic, together with pRL-TK control vector. After transfection for 24 h, the transfected HepG2 cells were cultured with CITCO $(10 \mu \mathrm{M})$ or vehicle DMSO (0.1\%) for an additional $24 \mathrm{~h}$ (A). The HepG2 cells were transiently co-transfected with pcDNA 3.1 (+)-hCAR expression vector, pGL3-UGT1A1-luc reporter vector, and pRL-TK control vector. After transfection for $24 \mathrm{~h}$, the transfected HepG2 cells were cultured with OA (10, 20, and $40 \mu \mathrm{M}), \mathrm{UA}(10,20$, and $40 \mu \mathrm{M})$, CITCO $(10 \mu \mathrm{M})$, or DMSO $(0.1 \%)$ for an additional $24 \mathrm{~h}$ (B). Luciferase activity was measured using the dual-luciferase reporter assay system. The transfection efficiency was normalized against renilla luciferase activity from the co-transfected $\mathrm{pRL}-\mathrm{TK}$ vector. DMSO $(0.1 \%)$ was used as the negative control. CITCO $(10 \mu \mathrm{M})$ was used as the positive control. The data are expressed as the mean \pm SD of triplicate independent experiments $\left({ }^{* *} \mathrm{p}<0.01\right)$.

TABLE 2 | The relative luciferase activity of PXR-mediated UGT1A1 reporter gene (Mean $\pm S D, n=3)$.

\begin{tabular}{lrr}
\hline Component & & Group \\
\cline { 2 - 3 } & Control & RIF (10 $\boldsymbol{\mu M}$ ) \\
\hline pcDNA3.1(+)-hPXR+pGL3-UGT1A1-LuC+pRL-TK & $0.101 \pm 0.013$ & $0.311 \pm 0.034$ \\
pCDNA3.1(+)+pGL3-UGT1A1+pRL-TK & $0.094 \pm 0.007$ & $0.137 \pm 0.018$ \\
pCDNA3.1(+)-hPXR+pGL3-Basic+pRL-TK & $0.083 \pm 0.010$ & $0.094 \pm 0.014$ \\
pcDNA3.1(+)+pGL3-Basic+pRL-TK & $0.078 \pm 0.012$ & $0.075 \pm 0.010$ \\
\end{tabular}

TABLE 3 | The relative luciferase activity of CAR-mediated UGT1A1 reporter gene (Mean $\pm S D, n=3)$.

\begin{tabular}{|c|c|c|c|}
\hline \multirow[t]{2}{*}{ Component } & \multicolumn{3}{|c|}{ Group } \\
\hline & Control & CITCO (10 $\mu \mathrm{M})$ & Fold induction \\
\hline pcDNA3.1(+)-hCAR+pGL3-UGT1A1-Luc+pRL-TK & $0.099 \pm 0.010$ & $0.189 \pm 0.028$ & $1.899 \pm 0.093$ \\
\hline pcDNA3.1(+)+pGL3-UGT1A1+pRL-TK & $0.096 \pm 0.008$ & $0.121 \pm 0.015$ & $1.262 \pm 0.047$ \\
\hline pcDNA3.1(+)-hCAR+pGL3-Basic+pRL-TK & $0.075 \pm 0.007$ & $0.086 \pm 0.012$ & $1.148 \pm 0.056$ \\
\hline pcDNA3.1(+)+pGL3-Basic+pRL-TK & $0.081 \pm 0.002$ & $0.077 \pm 0.004$ & $0.959 \pm 0.065$ \\
\hline
\end{tabular}

\section{Effect of OA and UA on UGT1A1 mRNA and Protein Levels in hPXR-Silenced HepG2 Cells}

To further confirm that OA and UA may induce PXR-mediated UGT1A1 expression in HepG2 cells, we successfully constructed an hPXR-silenced HepG2 cell model. Figure $\mathbf{7} \mathbf{A}_{\mathbf{1}}$ shows that the expression of PXR mRNA in hPXR-silenced HepG2 cells was downregulated by $69 \%$ compared to the control group, and PXR protein was also markedly downregulated by $61 \%$ (Figures $7 \mathbf{B}_{1}, \mathbf{C}_{1}$ ).
Subsequently, we examined the effects of OA and UA on the UGT1A1 mRNA and protein expression in hPXRsilenced HepG2 cells (Figures $\mathbf{7} \mathbf{A}_{2}-\mathbf{C}_{2}$ and Figures $\mathbf{7} \mathbf{A}_{3}-\mathbf{C}_{3}$ ). Compared to the control group (DMSO), RIF $(10 \mu \mathrm{M})$, OA $(40 \mu \mathrm{M})$, and UA $(40 \mu \mathrm{M})$ exhibited a weak induction on UGT1A1 mRNA and protein expression in hPXR-silenced HepG2 cells, whereas treatment with OA (10 and $20 \mu \mathrm{M})$ and UA $(10$ and $20 \mu \mathrm{M})$ did not influence the expression of UGT1A1. Moreover, UGT1A1 mRNA and protein expression 

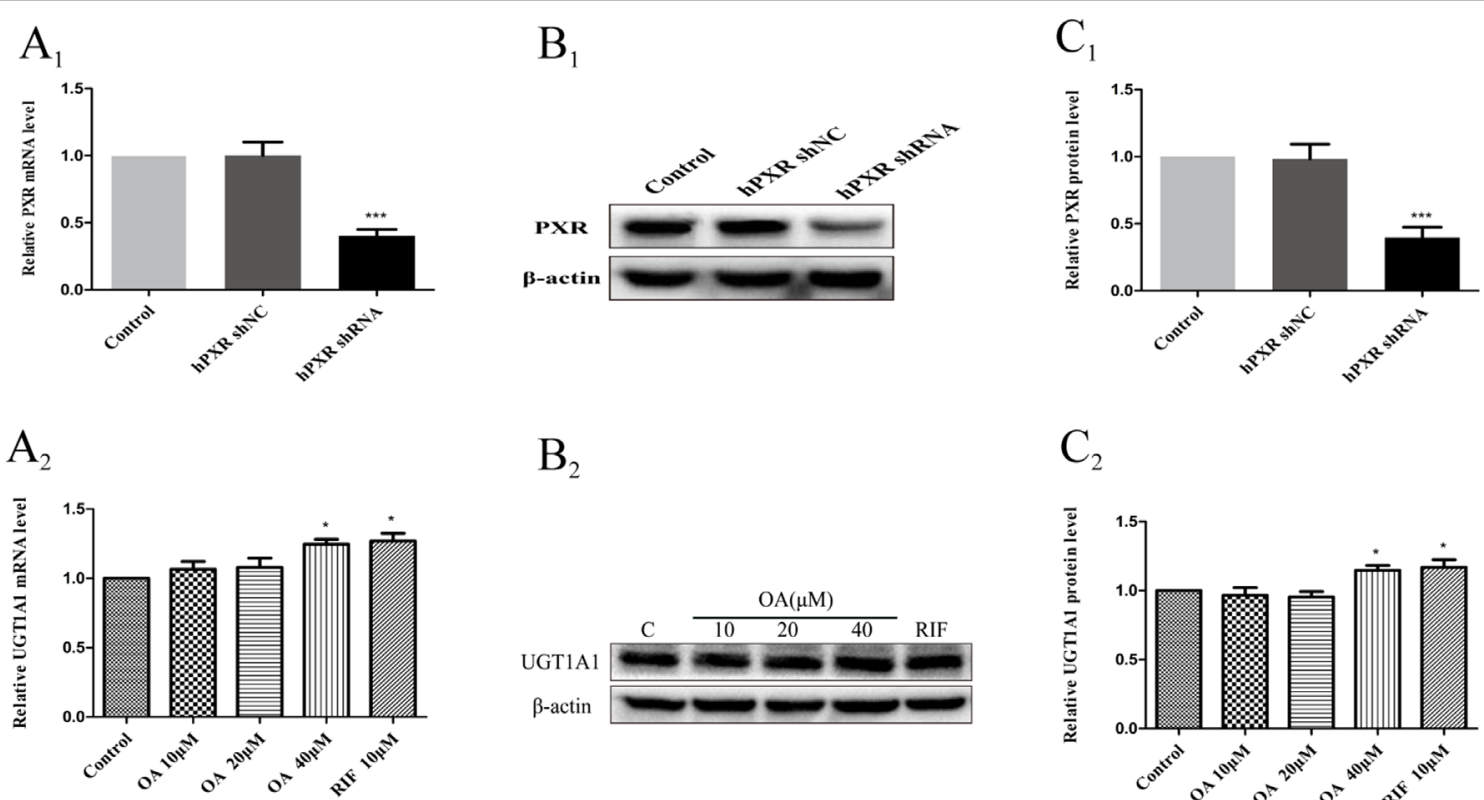

$\mathrm{B}_{2}$

$\mathrm{C}_{2}$
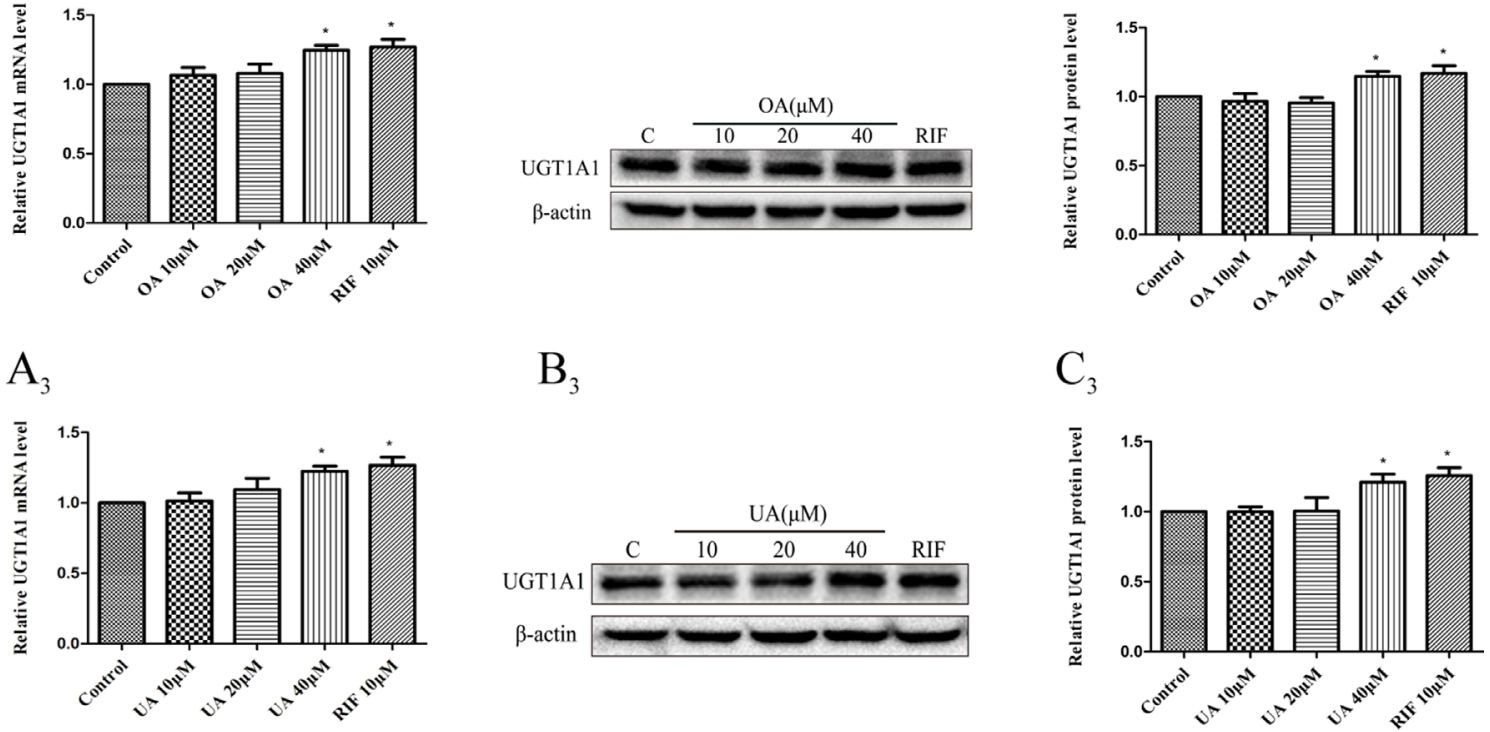

FIGURE 7 | Effect of OA and UA on UGT1A1 mRNA and protein in hPXR-silenced HepG2 cells. PXR mRNA and protein expression in HepG2 cells transfected with hPXR shRNA or hPXR shNC were determined by real-time Q-PCR analysis $\left(\mathbf{A}_{1}\right)$ and Western blotting analysis $\left(\mathbf{B}_{1}-\mathbf{C}_{1}\right)$, respectively. The HepG2 cells transfected with hPXR shRNA were treated with OA (10, 20, and $40 \mu \mathrm{M})\left(\mathbf{A}_{\mathbf{2}}-\mathbf{C}_{2}\right)$ and $U A(10,20$, and $40 \mu \mathrm{M})\left(\mathbf{A}_{3}-\mathbf{C}_{3}\right)$ for 24 h. UGT1A1 mRNA and protein expression in hPXR-silenced HepG2 cells treated with OA and UA were determined by real-time Q-PCR analysis (A) and Western blotting analysis (B, C), respectively. The determination of mRNA and nuclear protein was normalized to GAPDH and $\beta$-actin, respectively. DMSO (0.1\%) was used as the negative control. RIF (10 $\mu \mathrm{M})$ was used as the positive control. The data are expressed as the mean \pm SD of triplicate independent experiments $\left({ }^{*} \mathrm{p}<0.05,{ }^{\star \star *} \mathrm{p}<0.001\right)$.

in hPXR-silenced HepG2 cells treated with OA (10, 20, and $40 \mu \mathrm{M})$ and $\mathrm{UA}(10,20$, and $40 \mu \mathrm{M})$ significantly decreased compared to the non-silenced HepG2 cells. The above results indicated that the induction of OA and UA on UGT1A1 was mainly mediated by PXR.

\section{Effect of OA and UA on UGT1A1 mRNA and Protein Levels in hCAR-Silenced HepG2 Cells}

To further confirm whether CAR take part in the regulation of UGT1A1 in HepG2 cells treated with OA $(10,20$, and $40 \mu \mathrm{M})$ and UA $(10,20$, and $40 \mu \mathrm{M})$, we successfully constructed an hCARsilenced HepG2 cell model. Compared to the control group, the expression of CAR mRNA in hCAR-silenced HepG2 cells was downregulated by $67 \%$ (Figure $\mathbf{8 A _ { 1 }}$ ), and CAR protein was also markedly reduced (Figures $\mathbf{8} B_{1}, \mathbf{C}_{1}$ ).
Next, UGT1A1 mRNA and protein expression in hCARsilenced HepG2 cells treated with OA $(10,20$, and $40 \mu \mathrm{M})$ and UA $(10,20$, and $40 \mu \mathrm{M})$ were detected by real-time PCR and Western blotting, respectively. Compared to the blank control that was treated with DMSO, UGT1A1 mRNA and protein levels in hCAR-silenced HepG2 cells were significantly elevated when

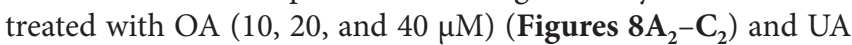
$(10,20$, and $40 \mu \mathrm{M})$ (Figures $\mathbf{8 A}_{3}-\mathbf{C}_{3}$ ). However, the UGT1A1 mRNA and protein expression in hCAR-silenced HepG2 cells treated with $\mathrm{OA}(10,20$, and $40 \mu \mathrm{M})$ and $\mathrm{UA}(10,20$, and $40 \mu \mathrm{M})$ did not significantly change compared to that in non-silenced HepG2 cells. The inductive effect of CITCO $(10 \mu \mathrm{M})$ on UGT1A1 mRNA and protein expression in hCAR-silenced HepG2 cells was significantly lower than that in normal HepG2 cells (Figures $\mathbf{8} \mathbf{A}_{2}-\mathbf{C}_{2}$ and Figures $\mathbf{8}_{3}-\mathbf{C}_{3}$ ). These results indicated that $\mathrm{OA}$ and UA had no influence on the UGT1A1 target gene mediated by CAR. 

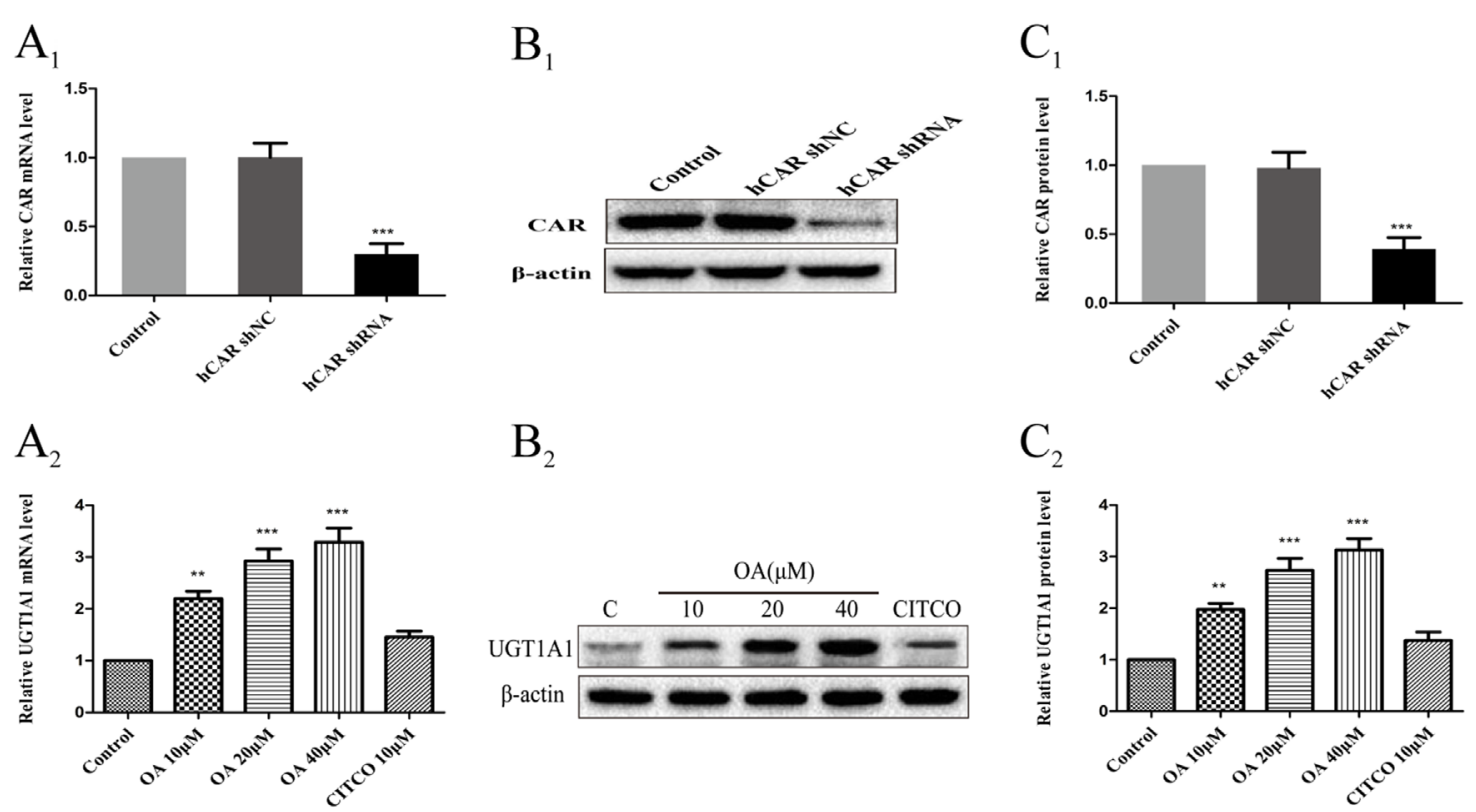

$\mathrm{B}_{2}$

$\mathrm{C}_{2}$
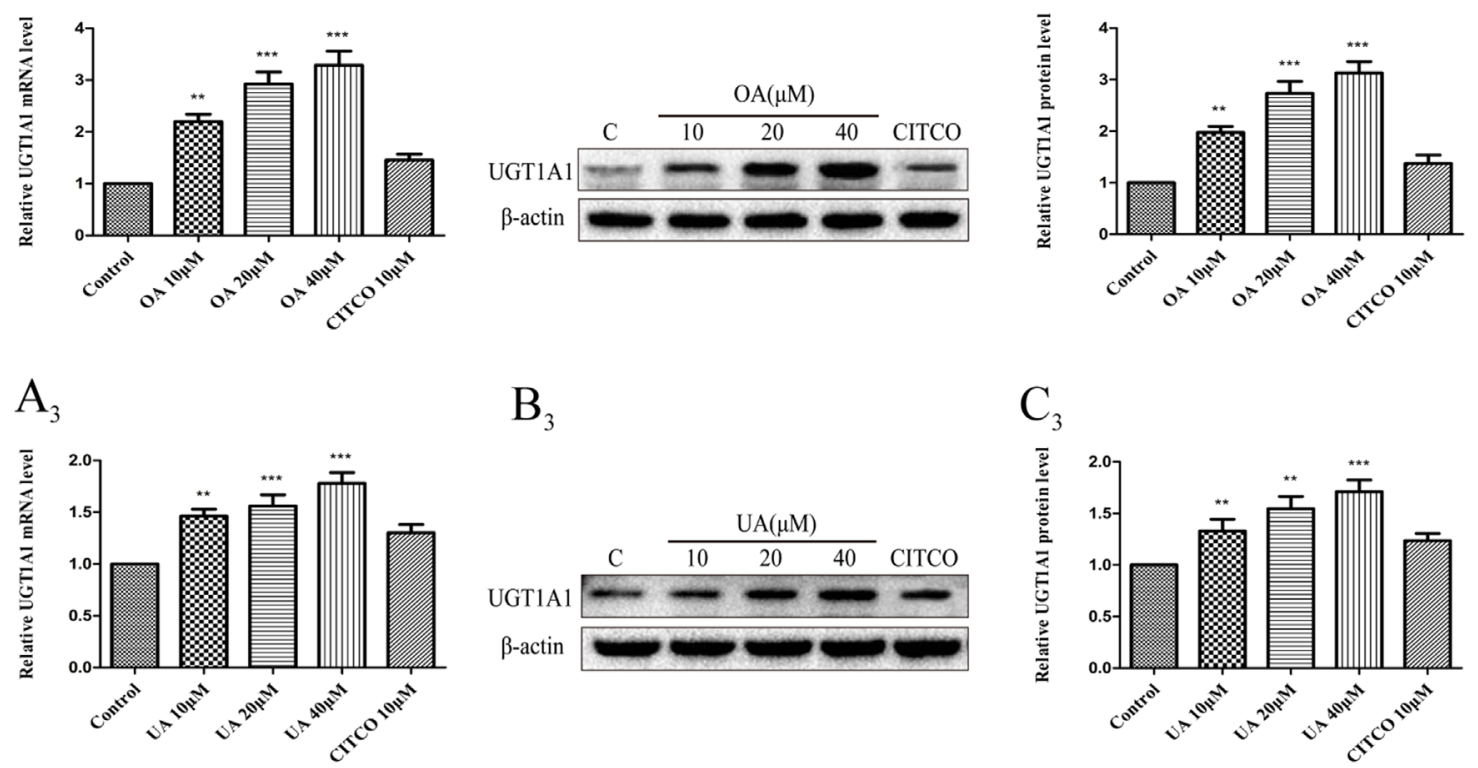

$\mathrm{B}_{3}$

$\mathrm{C}_{3}$
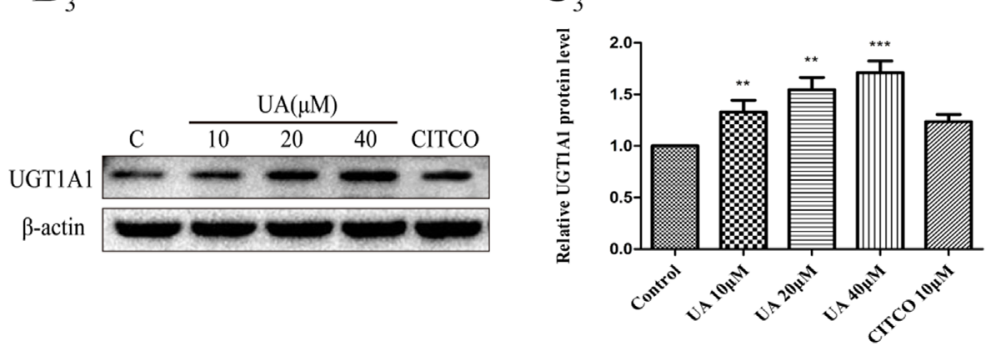

FIGURE 8 | Effect of OA and UA on UGT1A1 mRNA and protein in hCAR-silenced HepG2 cells. CAR mRNA and protein expression in HepG2 cells transfected with hCAR shRNA or hCAR shNC were determined by real-time Q-PCR analysis $\left(\mathbf{A}_{1}\right)$ and Western blotting analysis $\left(\mathbf{B}_{1}-\mathbf{C}_{1}\right)$, respectively. Then the HepG2 cells transfected with hCAR shRNA were treated with $\mathrm{OA}(10,20$, and $40 \mu \mathrm{M})\left(\mathbf{A}_{2}-\mathbf{C}_{2}\right)$ and $\mathrm{UA}(10,20$, and $40 \mu \mathrm{M})\left(\mathbf{A}_{3}-\mathbf{C}_{3}\right)$ for $24 \mathrm{~h}$. UGT1A1 mRNA and protein expression in hCAR-silenced HepG2 cells treated with OA and UA were determined by real-time Q-PCR analysis (A) and Western blotting analysis (B-C), respectively. The determination of mRNA and nuclear protein was normalized to GAPDH and $\beta$-actin, respectively. DMSO $(0.1 \%)$ was used as the negative control. CITCO $(10 \mu \mathrm{M})$ was used as the positive control. The data are expressed as the mean $\pm \mathrm{SD}$ of triplicate independent experiments $\left({ }^{\star \star} \mathrm{p}<0.01,{ }^{\star \star \star} \mathrm{p}<0.001\right)$.

\section{DISCUSSION}

Several studies have shown that nuclear receptors, especially PXR and CAR, play an important role in the regulation of UGTs, which are involved in the metabolism of various clinical drugs (Tolson and Wang, 2010). UGT1As are highly expressed in the liver and extrahepatic tissues, including UGT1A1, UGT1A3, UGT1A4, UGT1A6, UGT1A7, UGT1A8, UGT1A9, and UGT1A10 (Tukey and Strassburg, 2000; Nakamura et al., 2008). In our study, it was found that the concentrations of UA and OA ranged from 10-40 $\mu \mathrm{M}$ were all non-cytotoxic to HepG2 cells by MTT assay (data not shown). The subsequent studies showed that $\mathrm{OA}(10,20$, and $40 \mu \mathrm{M})$ and $\mathrm{UA}(10,20$, and $40 \mu \mathrm{M})$ significantly upregulated the expression of UGT1A1, UGT1A3, UGT1A4, and UGT1A9 mRNA and protein in HepG2 cells. These results indicated both $\mathrm{OA}$ and UA exhibited strong induction on UGT1A1, UGT1A3, UGT1A4, and UGT1A9, and there could be potential drug-drug interactions when $\mathrm{OA}$ and UA are co-administered with the substrate drugs of UGT1As. Similar inductive effects of OA and UA on UGT1As may be attributed to the fact that OA and UA are isomers and have similar chemical structures and activities (Kashyap et al., 2016). Seow and Lau (2017) also found UA activated PXR and increased UGT1A3 mRNA expression in human HepG2 and LS180 cells. Furthermore, the effect of UGT1As induced by $\mathrm{OA}$ and UA coincided at the mRNA and protein levels, which suggested that $\mathrm{OA}$ and UA induced the basal expression of UGT1As mRNA through transcriptional activation and then induced the expression of protein.

Several studies have confirmed that the activity of UGT1A1 is closely related to CAR or PXR, and UGT1A1 is involved in the metabolism of many drugs and important endogenous 
substances (Sugatani et al., 2005; Yeh et al., 2016). Therefore, we selected UGT1A1 as the representative of UGTs in the following study to explore how OA and UA regulate UGT1As based on the PXR and CAR signaling pathway. In this study, we found that both OA $(10,20$, and $40 \mu \mathrm{M})$ and $\mathrm{UA}(10,20$, and $40 \mu \mathrm{M})$ significantly increased the expression of PXR mRNA and protein in HepG2 cells in a concentration-dependent manner compared to the control group. However, both $\mathrm{OA}(10,20$, and $40 \mu \mathrm{M})$ and UA $(10,20$, and $40 \mu \mathrm{M})$ showed no significant impact on CAR mRNA and protein levels in HepG2 cells. In addition, the induction trend of UA and OA on UGT1A1 was in line with that on PXR. Based on the above results, we conclude that the induction of UGT1A1 by OA and UA may be mediated by activating PXR rather than CAR.

To verify the above hypotheses, we further investigated whether OA and UA could induce the PXR/CAR-mediated transactivation of the UGT1A1 by the dual-luciferase reporter assay system. The 290-bp element as a multi-component enhancer is a complex array of transcription factor-binding sites that contain a DR4 element, CAR response element (CARE), DR3 element, and PXR response element (PXRE) (Xie et al., 2003). In the reporter gene assay, the finding that RIF induced the PXR-mediated transactivation of the UGT1A1 290-bp reporter gene (Figures 5A, B) supports the fact that RIF is a known inducer of UGT1A1 both in vitro (Jemnitz et al., 2002) and in vivo (Adachi et al., 1985). Similarly, CITCO induced the CAR-mediated transactivation of the UGT1A1 290-bp reporter gene (Figures 6A, B). Meanwhile, both $\mathrm{OA}(10,20$, and $40 \mu \mathrm{M})$ and $\mathrm{UA}(10,20$, and $40 \mu \mathrm{M})$ could induce the PXR-mediated transactivation of the UGT1A1 290-bp reporter gene in a concentration-dependent manner compared to the control group. However, there were no significant impacts on CAR-mediated transactivation of UGT1A1 290-bp reporter gene in HepG2 cells treated with OA $(10,20$, and $40 \mu \mathrm{M})$ and UA $(10,20$, and $40 \mu \mathrm{M})$, respectively. These experimental data further supported that both OA and UA can induce UGT1A1 by activating PXR rather than CAR.

To further validate the above hypothesis, an RNA interference experiment was conducted in our study. We observed that the activation efficiency of the UGT1A1 gene in hPXR-silenced HepG2 cells treated with OA $(10,20$, and $40 \mu \mathrm{M})$ and UA (10, 20 , and $40 \mu \mathrm{M}$ ) were significantly reduced compared to the non-silenced HepG2 cells. Knocking down PXR expression by shRNA nearly abolished the induction of OA and UA on UGT1A1. We concluded that PXR activation is critical for the induction of UA and OA on UGT1A1. However, there were no significant differences in the activation efficiency of UGT1A1 in hCAR-silenced HepG2 cells treated with OA $(10,20$, and $40 \mu \mathrm{M})$ and UA $(10,20$, and $40 \mu \mathrm{M})$ compared to non-silenced HepG2 cells. Knocking down CAR expression by shRNA did not affect the effect of OA and UA on the UGT1A1 gene. The presence or absence of CAR has no influence on the activation efficiency of UGT1A1 by OA and UA. Therefore, we concluded that OA and UA induce UGT1A1 by activating PXR rather than CAR.

Previous studies have discovered that the UGT1A1 gene contained both CAR and PXR-binging motifs in its promoter region (Maglich et al., 2002; Xie et al., 2003).
Among nuclear receptors, PXR and CAR exhibit promiscuous xenobiotic activation capability. Hiura et al. (2014) found that 3-hydroxyflavone can induce UGT1A1 expression via PXR in LS180 cells. Roscovitine inhibits phosphorylation of PXR at Ser350 by CDK2 and enhances the translocation of PXR from the cytoplasm to the nucleus, resulting in elevated expression of UGT1A1 (Sugatani et al., 2012). However, phenobarbital treatment for hyperbilirubinemia has been known to increase the expression of the UGT1A1 gene by activating CAR in the liver and show an activity to a 290-bp distal enhancer sequence $(-3483 /-3194)$ of the human UGT1A1 gene (Sugatani et al., 2001). Recent studies have demonstrated that PXR and CAR regulate overlapping but distinct sets of genes involved in xenobiotic detoxification (Maglich et al., 2002). Compared to other NRs, PXR possesses a bulky and flexible ligand-binding cavity, which enables it to accommodate a more structurally promiscuous library of ligands (Watkins and Redinbo, 2001; $\mathrm{Xu}$ et al., 2004). This supports our conclusion that OA and UA induce UGT1A1 expression by activating PXR rather than CAR. The differential effect mechanism of UA and OA on PXR and CAR is worthy of further study in our future work.

Some previous studies (Kim et al., 2004; Chang et al., 2017) have suggested the links between cytochrome p450 enzymes and $\mathrm{OA}$ and/or UA. The metabolites of OA and/or UA mediated by CYP450s may also cause the change (suppression or induction) of UGTs. However, some CYP450 isoenzymes are hardly expressed in HepG2 cells such as CYP2E1. Therefore, it is needed to investigate the effect of UA and OA on UGTs using human primary hepatocytes in the incoming study.

In summary, OA and UA can induce the expression of UGT1A1, UGT1A3, UGT1A4, and UGT1A9 in HepG2 cells, and there are some potential drug-drug interactions when OA and UA are co-administered with clinical drugs of UGT1As substrates. OA and UA induced UGT1A1 expression by activating PXR rather than CAR. Additional studies are needed to assess the physiological significance of OA- and UA-activated PXR in animal models.

\section{DATA AVAILABILITY STATEMENT}

The raw data supporting the conclusions of this manuscript will be made available by the authors, without undue reservation, to any qualified researcher.

\section{AUTHOR CONTRIBUTIONS}

Participated in research design: CX, CZ and YX. Conducted experiments: NY, TZ, CZ, FH and ML. Performed data analysis: NY, FL, HZ and CX. Wrote or contributed to the writing of the manuscript: NY and CX.

\section{FUNDING}

This work was supported by China National Nature Science Fund (Nos. 81560606 and 81760672). 


\section{REFERENCES}

Adachi, Y., Nanno, T., Yamashita, M., Ueshima, S., and Yamamoto, T. (1985). Induction of rat liver bilirubin-conjugating enzymes and glutathione S-transferase by rifampicin. Gastroenterol. Jpn. 20, 104-110. doi: 10.1007/BF02776672

Bock, K. W. (2010). Functions and transcriptional regulation of adult human hepatic UDP-glucuronosyl-transferases (UGTs): mechanisms responsible for interindividual variation of UGT levels. Biochem. Pharmacol. 80, 771-777. doi: 10.1016/j.bcp.2010.04.034

Chang, H. Y., Chen, C. J., Ma, W. C., Cheng, W. K., Lin, Y. N., Lee, Y. R., et al. (2017). Modulation of pregnane $\mathrm{X}$ receptor (PXR) and constitutive androstane receptor (CAR) activation by ursolic acid (UA) attenuates rifampin-isoniazid cytotoxicity. Phytomedicine 36, 37-49. doi: 10.1016/j.phymed.2017.09.016

Gao, R., Liu, M., Chen, Y., Xia, C., Zhang, H., Xiong, Y., et al. (2016). Identification and characterization of human UDP-glucuronosyltransferases responsible for the in vitro glucuronidation of ursolic acid. Drug Metab. Pharmacokinet. 31, 261-268. doi: 10.1016/j.dmpk.2015.11.010

Haberkorn, V., Heydel, J. M., Mounie, J., Artur, Y., and Goudonnet, H. (2002). Vitamin A modulates the effects of thyroid hormone on UDPglucuronosyltransferase expression and activity in rat liver. Mol. Cell Endocrinol. 190, 167-175. doi: 10.1016/S0303-7207(01)00681-5

Hiura, Y., Satsu, H., Hamada, M., and Shimizu, M. (2014). Analysis of flavonoids regulating the expression of UGT1A1 via xenobiotic receptors in intestinal epithelial cells. Biofactors 40, 336-345. doi: 10.1002/biof.1153

Jemnitz, K., Lengyel, G., and Vereczkey, L. (2002). In vitro induction of bilirubin conjugation in primary rat hepatocyte culture. Biochem. Bioph. Res. 291, 29-33. doi: 10.1006/bbrc.2002.6400

Kapitanović, S., Ivković, T. C., Jakovljević, G., and Giljević, J. S. (2009). Etoposide/ platinum therapy, UGT1A1 and GSTP1 polymorphisms and toxicity in childrens with solid tumors. Eur. J. Cancer Supplements 7, 21. doi: 10.1016/ S1359-6349(09)72175-5

Kashyap, D., Sharma, A., Tuli, H. S., Punia, S., and Sharma, A. K. (2016). Ursolic acid and oleanolic acid: pentacyclic terpenoids with promising antiinflammatory activities. Recent Pat. Inflamm. Allergy Drug Discov. 10, 21-33. doi: 10.2174/1872213X10666160711143904

Kim, K. A., Lee, J. S., Park, H. J., Kim, J. W., Kim, C. J., Shim, I. S., et al. (2004). Inhibition of cytochrome P450 activities by oleanolic acid and ursolic acid in human liver microsomes. Life Sci. 74 (22), 2769-2779. doi: 10.1016/j.lfs.2003.10.020

Kliewer, S. A., Moore, J. T., Wade, L., Staudinger, J. L., Watson, M. A., Jones, S. A., et al. (2015). An orphan nuclear receptor activated by pregnanes defines a novel steroid signaling pathway. Cell 92, 73-82. doi: 10.1016/ S0092-8674(00)80900-9

Mackenzie, P. I., Bock, K. W., Burchell, B., Guillemette, C., Ikushiro, S., Iyanagi, T., et al. (2005). Nomenclature update for the mammalian UDP glycosyltransferase (UGT) gene superfamily. Pharmacogenet. Genom. 15, 677. doi: 10.1097/01. fpc.0000173483.13689.56

Maglich, J. M., Stoltz, C. M., Goodwin, B., Hawkinsbrown, D., Moore, J. T., and Kliewer, S. A. (2002). Nuclear pregnane $\mathrm{x}$ receptor and constitutive androstane receptor regulate overlapping but distinct sets of genes involved in xenobiotic detoxification. Mol. Pharmacol. 62, 638-646. doi: 10.1124/mol.62.3.638

Manevski, N., Troberg, J., Svaluto-Moreolo, P., Dziedzic, K., Yli-Kauhaluoma, J., and Finel, M. (2013). Albumin stimulates the activity of the human UDPglucuronosyltransferases $1 \mathrm{~A} 7,1 \mathrm{~A} 8,1 \mathrm{~A} 10,2 \mathrm{~A} 1$ and $2 \mathrm{~B} 15$, but the effects are enzyme and substrate dependent. PLoS One 8, e54767. doi: 10.1371/journal. pone. 0054767

Nakamura, A., Nakajima, M., Yamanaka, H., Fujiwara, R., and Yokoi, T. (2008). Expression of UGT1A and UGT2B mRNA in human normal tissues and various cell lines. Drug Metab. Dispos. 36, 1461-1464. doi: 10.1124/dmd.108.021428

Seow, C. L., and Lau, A. J. (2017). Differential activation of pregnane X receptor by carnosic acid, carnosol, ursolic acid, and rosmarinic acid. Pharmacol. Res. 120, 23-33. doi: 10.1016/j.phrs.2017.03.007

Stanley, L. A., Horsburgh, B. C., Ross, J., Scheer, N., and Wolf, C. R. (2006). PXR and CAR: Nuclear receptors which play a pivotal role in drug disposition and chemical toxicity. Drug Metab. Rev. 38, 515-597. doi: 10.1080/03602530600786232

Street, C. M., Zhu, Z., Finel, M., and Court, M. H. (2017). Bisphenol-A glucuronidation in human liver and breast: identification of UDPglucuronosyltransferases (UGTs) and influence of genetic polymorphisms. Xenobiotica 47, 1-10. doi: 10.3109/00498254.2016.1156784
Sugatani, J., Kojima, H., Ueda, A., Kakizaki, S., Yoshinari, K., Gong, Q. H., et al. (2001). The phenobarbital response enhancer module in the human bilirubin UDP - glucuronosyltransferase UGT1A1 gene and regulation by the nuclear receptor CAR. Hepatology 33, 1232-1238. doi: 10.1053/jhep.2001.24172

Sugatani, J., Nishitani, S., Yamakawa, K., Yoshinari, K., Sueyoshi, T., Negishi, M., et al. (2005). Transcriptional regulation of human UGT1A1 gene expression: activated glucocorticoid receptor enhances constitutive androstane receptor/ pregnane X receptor-mediated UDP-glucuronosyltransferase 1A1 regulation with glucocorticoid receptor-interacting protein 1. Mol. Pharmacol. 67, 845855. doi: 10.1124/mol.104.007161

Sugatani, J., Uchida, T., Kurosawa, M., Yamaguchi, M., Yamazaki, Y., Ikari, A., et al. (2012). Regulation of pregnane X receptor (PXR) function and UGT1A1 gene expression by posttranslational modification of PXR protein. Drug Metab. Dispos. 40, 2031. doi: 10.1124/dmd.112.046748

Sugatani, J., Yamakawa, K., Tonda, E., Nishitani, S., Yoshinari, K., Degawa, M., et al. (2004). The induction of human UDP-glucuronosyltransferase 1A1 mediated through a distal enhancer module by flavonoids and xenobiotics. Biochem. Pharmacol. 67, 989-1000. doi: 10.1016/j.bcp.2003.11.002

Takano, M., and Sugiyama, T. (2017). UGT1A1 polymorphisms in cancer: impact on irinotecan treatment. Pharmgenomics Pers. Med. 10, 61-68. doi: 10.2147/ PGPM.S108656

Tolson, A. H., and Wang, H. (2010). Regulation of drug-metabolizing enzymes by xenobiotic receptors: PXR and CAR. Adv. Drug Deliv. Rev. 62, 1238-1249. doi: 10.1016/j.addr.2010.08.006

Tukey, R. H., and Strassburg, C. P. (2000). Human UDP-glucuronosyltransferases: metabolism, expression, and disease. Annu. Rev. Pharmacol. Toxicol. 40, 581616. doi: 10.1146/annurev.pharmtox.40.1.581

Victor, A. M., Bernhard, S., Zeng-Xia, L. I., Sonja, S., Hermann, S., Elisabeth, I., et al. (2015). Ursolic acid fromTrailliaedoxa gracilisinduces apoptosis in medullary thyroid carcinoma cells. Mol. Med. Rep. 12, 5003-5011. doi: 10.3892/ mmr.2015.4053

Watkins, R. E., and Redinbo, M. R. (2001). The human nuclear xenobiotic receptor PXR: structural determinants of directed promiscuity. Science 292, 2329-2333. doi: 10.1126/science.1060762

Wen,Z., Tallman,M.N.,Ali,S.Y., andSmith,P.C.(2007).UDP-glucuronosyltransferase $1 \mathrm{~A} 1$ is the principal enzyme responsible for etoposide glucuronidation in human liver and intestinal microsomes: structural characterization of phenolic and alcoholic glucuronides of etoposide and estimation of enzyme kinetics. Drug Metab. Dispos. 35, 371. doi: 10.1124/dmd.106.012732

Xie, H., Wu, J., Liu, D., Liu, M., Zhang, H., Huang, S., et al. (2017). In vitro inhibition of UGT1A3, UGT1A4 by ursolic and oleanolic acid and drug-drug interaction risk prediction. Xenobiotica 47, 1-28. doi: 10.1080/00498254.2016.1234087

Xie, W., Yeuh, M. F., Radominskapandya, A., Saini, S. P. S., Negishi, Y., Bottroff, B. S., et al. (2003). Control of steroid, heme, and carcinogen metabolism by nuclear pregnane $\mathrm{X}$ receptor and constitutive androstane receptor. Pro. Natl. Acad. Sci. U. S. A. 100, 4150-4155. doi: 10.1073/pnas.0438010100

Xu, R. X., Lambert, M. H., Wisely, B. B., Warren, E. N., Weinert, E. E., Waitt, G. M., et al. (2004). A Structural Basis for Constitutive Activity in the Human CAR/RXRa Heterodimer. Mol. Cell 16, 919-928. doi: 10.1016/j. molcel.2004.11.042

Yeh, Y. S., Tsai, H. L., Huang, C. W., Wang, J. H., Lin, Y. W., Tang, H. C., et al. (2016) Prospective analysis of UGT1A1promoter polymorphism for irinotecan dose escalation in metastatic colorectal cancer patients treated with bevacizumab plus FOLFIRI as the first-line setting: study protocol for a randomized controlled trial. Trials 17, 46. doi: 10.1186/s13063-016-1153-3

Conflict of Interest: The authors declare that the research was conducted in the absence of any commercial or financial relationships that could be construed as a potential conflict of interest.

Copyright (c) 2019 Yao, Zeng, Zhan, He, Liu, Liu, Zhang, Xiong and Xia. This is an open-access article distributed under the terms of the Creative Commons Attribution License (CC BY). The use, distribution or reproduction in other forums is permitted, provided the original author(s) and the copyright owner(s) are credited and that the original publication in this journal is cited, in accordance with accepted academic practice. No use, distribution or reproduction is permitted which does not comply with these terms. 